\title{
Analyses of the local control of pulmonary Oligometastases after stereotactic body radiotherapy and the impact of local control on survival
}

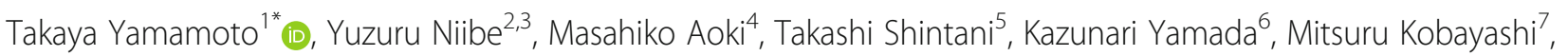
Hideomi Yamashita ${ }^{8}$, Masatoki Ozaki ${ }^{9}$, Yoshihiko Manabe ${ }^{10}$, Hiroshi Onishi ${ }^{11}$, Katsuya Yahara ${ }^{12}$, Atsushi Nishikawa ${ }^{13}$, Kuniaki Katsui ${ }^{14}$, Ryoong-Jin Oh ${ }^{15}$, Atsuro Terahara ${ }^{2}$ and Keiichi Jingu ${ }^{1}$

\begin{abstract}
Background: Successful local therapy for oligometastases may lead to longer survival. The purpose of this multicentre retrospective study was to investigate factors affecting the local control (LC) of pulmonary oligometastases treated by stereotactic body radiotherapy (SBRT) and to investigate the impact of LC on survival.

Methods: The inclusion criteria included 1 to 5 metastases, the primary lesion and other extrathoracic metastases were controlled before SBRT, and the biological effective dose (BED 10 ) of the SBRT was 75 Gy or more. The Cox proportional hazards model was used for analyses.
\end{abstract}

Results: Data of 1378 patients with 1547 tumours from 68 institutions were analysed. The median follow-up period was 24.2 months. The one-year, 3-year and 5-year LC rates were 92.1, 81.3 and 78.6\%, respectively, and the 1-year, 3year and 5-year overall survival rates were 90.1, 60.3 and $45.5 \%$, respectively. Multivariate analysis for LC showed that increased maximum tumour diameter $(p=0.011)$, type A dose calculation algorithm $(p=0.005)$, shorter overall treatment time of SBRT $(p=0.035)$ and colorectal primary origin $(p<0.001$ excluding oesophagus origin) were significantly associated with a lower LC rate. In the survival analysis, local failure $(p<0.001)$, worse performance status ( 1 vs. $0, p=0.013 ; 2-3$ vs. $0, p<0.001$ ), oesophageal primary origin (vs. colorectal origin, $p=0.038$ ), squamous cell carcinoma (vs. adenocarcinoma, $p=0.006$ ) and increased maximum tumour diameter $(p<0.001)$ showed significant relationships with shorter survival.

Conclusions: Several factors of oligometastases and SBRT affected LC. LC of pulmonary oligometastases by SBRT showed a significant survival benefit compared to patients with local failure.

Keywords: Pulmonary oligometastases, Oligo-recurrence, Sync-oligometastases, Stereotactic body radiotherapy, Local control, Metastasis-directed therapy

\footnotetext{
* Correspondence: t.yamamoto@rad.med.tohoku.ac.jp

${ }^{1}$ Department of Radiation Oncology, Tohoku University Graduate School of

Medicine, 1-1 Seiryo-machi, Aoba-ku, Sendai 980-8574, Japan

Full list of author information is available at the end of the article
}

(c) The Author(s). 2020 Open Access This article is licensed under a Creative Commons Attribution 4.0 International License, which permits use, sharing, adaptation, distribution and reproduction in any medium or format, as long as you give appropriate credit to the original author(s) and the source, provide a link to the Creative Commons licence, and indicate if changes were made. The images or other third party material in this article are included in the article's Creative Commons licence, unless indicated otherwise in a credit line to the material. If material is not included in the article's Creative Commons licence and your intended use is not permitted by statutory regulation or exceeds the permitted use, you will need to obtain permission directly from the copyright holder. To view a copy of this licence, visit http://creativecommons.org/licenses/by/4.0/ The Creative Commons Public Domain Dedication waiver (http://creativecommons.org/publicdomain/zero/1.0/) applies to the data made available in this article, unless otherwise stated in a credit line to the data. 


\section{Background}

During the past few decades, increasing attention has been paid to the importance of controlling the primary site in metastatic disease. Some prospective trials and many retrospective studies of metastatic disease have shown improvement in the survival of patients treated with surgery or radiotherapy for the primary lesion, although systemic therapy has been the standard treatment [1-5]. In addition, aside from the activity of the primary lesion, a few metastases known as oligometastases, which might be good candidates for metastasisdirected therapy, have gradually been recognized [6]. The survival benefit of primary lesion control was only revealed in prostate cancer patients with a low metastatic burden (probably an oligometastatic state) [7]. Some phase 2 studies have revealed that intensive local therapy for the primary lesion and for all known oligometastases improved overall survival and disease-free survival of patients, and the results of a future phase 3 trial are awaited [8-10].

In any case, control of the primary lesion is important in the oligometastatic state, and therefore, the classification of oligometastases according to the activity of the primary lesion is important when metastasis-directed therapy is to be performed. Oligometastases have been classified into oligorecurrences and sync-oligometastases according to the activity of the primary lesion at the time of the initial appearance of oligometastases, and patients with oligo-recurrences have longer survival than those with sync-oligometastases [11, 12]. Recently, an investigation to determine whether there is a survival difference between patients with pulmonary oligorecurrences and patients with sync-oligometastases after establishing control of the primary lesion was performed in Japan, and it was shown by our group that patients with oligo-recurrences had a survival advantage compared with those with sync-oligometastases [13]. The next question is whether successful local therapy for pulmonary oligometastases leads to longer survival or not and what factors affect local control (LC).

The aim of this study was to identify factors affecting LC and to determine the survival benefit of LC after stereotactic body radiotherapy (SBRT) for pulmonary oligometastases. LC was the secondary endpoint, and this study was a secondary endpoint analysis. In addition, the effect of LC on survival was investigated through an exploratory survival analysis of this large survey.

\section{Methods}

\section{Eligibility and event definitions}

The inclusion criteria were as follows: SBRT for pulmonary oligometastases was performed between January 2004 and June 2015, the number of metastasis was limited to 1 to 5 at the time of the emergence of the SBRT- targeted tumour, the primary lesion and other extrathoracic lesions were controlled before SBRT was performed, and the biological effective dose $\left(\mathrm{BED}_{10}\right)$ of SBRT was $75 \mathrm{~Gy}$ or more and the dose per fraction was $4 \mathrm{~Gy}$ or more. When there were multiple oligometastases, combination treatment with SBRT for some oligometastases and surgery for other oligometastases was allowed. The exclusion criterion was local recurrence of a primary thoracic tumour. The following formula was used for the calculation of the $\mathrm{BED}_{10}: \mathrm{BED}=\mathrm{nd}[1+\mathrm{d} /(\alpha / \beta)]$, where $n$ is the number of fractions, $d$ is dose per fraction and the $\alpha / \beta$ ratio is 10 Gy for the tumours. Pulmonary oligometastasis was defined as the appearance of a solid tumour in the lung at the same time as or after treatment of the primary lesion. Local failure was defined as progression of the irradiated tumour which was based on Response Evaluation Criteria in Solid Tumors (RECI $\mathrm{ST}$ ) version 1.1 and further work-up such as ${ }^{18} \mathrm{~F}$-Fluorodeoxyglucose Positron Emission Tomography (FDGPET), biopsy or close follow-up CT scan was done when it was difficult to distinguish progression of the irradiated tumor from lung consolidation. Finally the judgement was done by doctors in charge of the primary disease and radiation oncologist. LC was defined as freedom from local failure, and the locally controlled cohort was defined as freedom from any local failure of the irradiated tumour.

\section{Ethics approval}

This study was a retrospective, multicentre study in Japan. This study was conducted in 68 institutions in Japan. All of the institutions were health insurancecovered medical institutions that cover all citizens in Japan. This study was approved by the ethical committee of a senior facility (Ethics Committee of Toho University Omori Medical Center, reference number: 27-148). The need for informed consent was waived due to the study design, but all participating institutions were guaranteed the chance to opt-out of participating in this study by spreading information about the study via the Internet or posters, and opt-out consent was obtained from all patients.

\section{Statistical analysis}

Statistical analyses were performed using EZR, version 1.37 (Saitama Medical Center, Jichi Medical University, Saitama, Japan), a modified version of $\mathrm{R}$ commander ( $\mathrm{R}$ Foundation for Statistical Computing, Vienna, Austria) [14]. Time to event was calculated from the first day of SBRT to the day an event was confirmed. When no event occurred (local failure or death), the last date of survival (typically the last consultation day) was used as the last moment of follow-up. The cumulative LC and overall survival (OS) rates were calculated using the 
Kaplan-Meier method, and the 95\% confidence interval (95\% CI) was calculated using Greenwood's formula. The Cox proportional hazards model was adjusted for LC analyses, and variables with a $p$-value of $<0.200$ in the univariate analyses (UVA) were regarded as potential factors and were entered into the multivariate analysis (MVA) with a stepwise backward elimination/forward addition approach using the Akaike information criterion (AIC) to build the best MVA model. A p-value < 0.050 was defined as significant.

Analyses of pretreatment prognostic factors for OS (the primary endpoint) have been previously reported elsewhere [13]. In this study, LC analyses were performed as secondary endpoint analyses, and the impact of LC on survival was determined by exploratory survival analyses. Because local failure was the observed factor after SBRT, further analysis of OS was performed in this study to determine the effect of LC on OS. First, LC was analysed as a time-dependent covariate. Previously reported covariates selected by the stepwise approach without changing the continuous variables into categorical variables were used: performance status (PS), primary lesions, pathology of the primary lesion, oligometastatic state and maximum tumour diameter. Local status was forced into this multivariate model as a time-dependent covariate. Second, for the sensitivity analyses, the landmark analysis method was used [15, 16]. There was thought to be a time-to-failure bias that patients with local failure must survive at least until the time of the confirmation of local failure; in other words, the separation of the locally controlled and locally failed cohorts was affected by the follow-up period. Therefore, the landmark method was used: 6 months, 1 year, 2 years and 3 years were set as the landmark times, and all local failures after the landmark time and all deaths before that time were ignored. Then, a log-rank test was applied to compare locally controlled and locally failed cohorts with a $p$-value of $\leq 0.012$ denoting significance. Lung adverse events (AEs) were graded using the National Cancer Institute Common Terminology Criteria for Adverse Events version 4.0.

\section{Results}

\section{Patient characteristics}

A total of 1378 patients with 1547 tumours from 68 institutions were enrolled in this study. The baseline characteristics of the patients, primary tumours, oligometastatic tumours and SBRT are summarized in Table 1. PS and additional chemotherapy were judged at the timing of each SBRT if SBRT was performed asynchronously for two or more tumours. The dose calculation algorithm of type B was equivalent to the Analytical Anisotropic Algorithm, type $\mathrm{C}$ was equivalent to the Monte Carlo Algorithm and type A was an older generation algorithm, such as the Pencil Beam Convolution. More than half of oligometastatic tumours were treated with 4-fraction SBRT
(959 tumours), and the median overall treatment time (OTT) of 4-fraction SBRT was 5 days. The most typical prescription dose was $48 \mathrm{~Gy}$ in 4-fraction to the isocenter (372 tumours).

\section{Treatment outcomes}

The median follow-up period for all patients was 24.2 months (range, 0.1-143.6 months; interquartile range [IQR], 13.7-42.7 months), and that for survivors was 26.9 months (range, 0.1-143.6 months; IQR, 14.7-49.4 months). The estimated 1-year, 3-year and 5-year LC rates were $92.1 \%$ (95\% CI, 90.4-93.4\%), 81.3\% (95\% CI, $78.8-83.6 \%)$ and $78.6 \%$ (95\% CI, 75.6-81.2\%), respectively (Fig. 1). Local failure of the irradiated tumour occurred in 222 tumours, and the median interval from SBRT to local failure was 12.4 months (range, 2.9-98.6 months; IQR, 9.1-19.7 months). A total of 536 patients with 603 tumours died, and 10 deaths were caused by AEs of SBRT. The estimated 1-year, 3-year and 5-year OS rates were $90.1 \%$ (95\% CI, 88.3-91.6\%), 60.3\% (95\% CI, 57.1-63.3\%) and 45.5\% (95\% CI, 41.8-49.1\%), respectively (Fig. 1). The median survival period was 51.4 months (95\% CI, 45.0-55.7 months). There were lung AEs reports from 1200 tumours in 1040 patients. Of those patients, 122 patients with 143 tumours (11.7\%) had grade 2 or higher and 26 patients with 32 tumours (2.5\%) had grade 3 or higher. Among 10 patients who developed AEs of grade 5, 3 patients with 4 tumours had grade 5 haemoptysis, and grade 5 radiation pneumonitis occurred in 7 patients with 9 tumours who had the following features: 3 patients had coexisting interstitial pneumonia, 3 patients had received thoracic radiotherapy before or after SBRT and one patient had a solitary metastasis but an older age ( 87 years).

\section{Analyses for LC and survival}

The UVA results for LC are shown in Supplementary Table 1, and the MVA results for LC are shown in Table 2. Maximum tumour diameter (per 1-cm increase; hazard ratio $[\mathrm{HR}], 1.297 ; 95 \% \mathrm{CI}, 1.059-1.588 ; p=$ 0.011 ), type $\mathrm{B}$ dose calculation algorithm (ref. type A; HR, 0.592; 95\% CI, 0.410-0.856; $p=0.005)$, OTT of SBRT (per 10-day prolongation; HR, 0.610; 95\% CI, $0.385-0.966 ; p=0.035)$ and primary lesions emerged as significant factors, showing that a higher HR was related to a higher rate of local failure. In regard to primary lesions, the LC rate for oligometastases from colorectal cancer was significantly lower than the LC rate for oligometastases from lung cancer (ref. colorectum; HR, 0.413; 95\% CI, 0.274-0.622; $p<0.001$ ), head and neck cancer (ref. colorectum; HR, 0.194; 95\% CI, 0.077-0.489; $p<$ 0.001 ) and other cancers (ref. colorectum; HR, 0.337; 95\% CI, 0.208-0.546; $\mathrm{p}<0.001$ ), excluding oesophagus (ref. colorectum; HR, 0.618; 95\% CI, 0.306-1.248; $p=$ 
Table 1 Characteristics of patients, primary tumours, oligometastatic tumours and SBRT characteristics

\begin{tabular}{|c|c|c|}
\hline Characteristic & Distribution & Number (\%) \\
\hline All tumours & & 1547 \\
\hline \multirow[t]{2}{*}{ Sex } & Male & $994(64.3)$ \\
\hline & Female & $553(35.7)$ \\
\hline Age, years & Median, range, IQR & $72 ; 16-93 ; 63-78$ \\
\hline \multirow[t]{5}{*}{ ECOG Performance Status } & 0 & $841(54.4)$ \\
\hline & 1 & $529(34.2)$ \\
\hline & 2 & $90(5.8)$ \\
\hline & 3 & $19(1.2)$ \\
\hline & Missing & $68(4.4)$ \\
\hline \multirow[t]{5}{*}{ Primary lesion sites } & Lung & $451(29.2)$ \\
\hline & Colorectum & $391(25.3)$ \\
\hline & Head and Neck & $126(8.1)$ \\
\hline & Oesophagus & $132(8.5)$ \\
\hline & Others & $447(28.9)$ \\
\hline \multirow[t]{5}{*}{ Pathology of primary lesion } & Adenocarcinoma & $861(55.7)$ \\
\hline & Squamous cell carcinoma & $396(25.6)$ \\
\hline & Sarcoma & $47(3.0)$ \\
\hline & Others & $168(10.9)$ \\
\hline & Missing & $75(4.8)$ \\
\hline \multirow[t]{5}{*}{ Control method of primary lesion } & Surgery & $1222(79.0)$ \\
\hline & Chemoradiation & $130(8.4)$ \\
\hline & Radiation (X-ray or particle) & $70(4.5)$ \\
\hline & Others & $40(2.6)$ \\
\hline & Missing & $85(5.5)$ \\
\hline Disease-free interval, months & Median, range, IQR & $17.5 ; 0-423.9 ; 8.0-34.3$ \\
\hline \multirow[t]{4}{*}{ Oligometastatic state } & Oligo-recurrences & $1157(74.8)$ \\
\hline & Sync-oligometastases & $133(8.6)$ \\
\hline & Unclassified & $133(8.6)$ \\
\hline & Missing & $124(8.0)$ \\
\hline \multirow[t]{2}{*}{ SBRT performed institution } & Academic & $642(41.5)$ \\
\hline & Non-academic & $905(58.5)$ \\
\hline \multirow[t]{2}{*}{ Date SBRT was performed } & 2004-2009 & $518(33.5)$ \\
\hline & $2010-2015$ & $1029(66.5)$ \\
\hline \multirow[t]{3}{*}{ Chemotherapy } & Before SBRT & $\begin{array}{l}\text { Yes, } 591(38.2) \\
\text { No, } 945(61.1) \\
\text { Missing, } 11(0.7)\end{array}$ \\
\hline & Concurrent with SBRT & $\begin{array}{l}\text { Yes, } 34 \text { (2.2) } \\
\text { No, } 1513 \text { (97.8) }\end{array}$ \\
\hline & After SBRT & $\begin{array}{l}\text { Yes, } 242(15.6) \\
\text { No, } 998(64.5) \\
\text { Missing, } 307 \text { (19.9) }\end{array}$ \\
\hline Maximum tumour diameter, $\mathrm{cm}$ & Median, range, IQR & $1.5 ; 0.3-6.5 ; 1.0-2.0$ \\
\hline \multirow[t]{3}{*}{ Number of oligometastases at the time of emergence of the SBRT-targeted tumour } & 1 & $1036(67.0)$ \\
\hline & $2-5$ & $503(32.5)$ \\
\hline & Missing & $8(0.5)$ \\
\hline Lung lobe involved with treated tumour & Right upper lobe & $293(18.9)$ \\
\hline
\end{tabular}


Table 1 Characteristics of patients, primary tumours, oligometastatic tumours and SBRT characteristics (Continued)

\begin{tabular}{|c|c|c|}
\hline Characteristic & Distribution & Number (\%) \\
\hline & Right middle lobe & $83(5.4)$ \\
\hline & Right lower lobe & $321(20.8)$ \\
\hline & Left upper lobe & $294(19.0)$ \\
\hline & Left lower lobe & $226(14.6)$ \\
\hline & Unknown lobe & Right lung, 12; Left lung, 7 \\
\hline & Missing & $311(20.1)$ \\
\hline \multirow[t]{3}{*}{ Beams } & Multiple static & $1145(74.0)$ \\
\hline & Arc & $401(25.9)$ \\
\hline & Missing & $1(0.1)$ \\
\hline \multirow[t]{4}{*}{ X-ray energy } & $4 \mathrm{MV}$ only & $202(13.1)$ \\
\hline & $6 \mathrm{MV}$ only & $1179(76.2)$ \\
\hline & Others & $160(10.3)$ \\
\hline & Missing & $6(0.4)$ \\
\hline \multirow[t]{3}{*}{ Field coplanarity } & Coplanar field & $1139(73.6)$ \\
\hline & Non-coplanar field & $404(26.1)$ \\
\hline & Missing & $4(0.3)$ \\
\hline \multirow[t]{4}{*}{ Dose calculation algorithm } & Type A & $541(35.0)$ \\
\hline & Type B & $799(51.6)$ \\
\hline & Type C & $144(9.3)$ \\
\hline & Missing & $63(4.1)$ \\
\hline \multirow[t]{3}{*}{ Dose prescription } & IC & $1103(71.3)$ \\
\hline & D95 of PTV & $317(20.5)$ \\
\hline & Others & $127(8.2)$ \\
\hline $\mathrm{BED}_{10}$ at isocenter, Gy & Median, range, IQR & $105.6 ; 75.0-289.5 ; 105.6-126.9$ \\
\hline \multirow[t]{5}{*}{ Number of SBRT fractions } & $2-3$ & $27(1.7)$ \\
\hline & 4 & $959(62.0)$ \\
\hline & 5 & $236(15.3)$ \\
\hline & $6-16$ & $324(20.9)$ \\
\hline & missing & $1(0.1)$ \\
\hline OTT of SBRT, day & Median, range, IQR & $7 ; 3-81 ; 4-11$ \\
\hline
\end{tabular}

Abbreviations: SBRT Stereotactic body radiotherapy, IQR Interquartile range, ECOG Eastern Cooperative Oncology Group, IC Isocenter, D95 of PTV Dose covering $95 \%$ of planning target volume, BED Biological effective dose, OTT Overall treatment time

0.179). Kaplan-Meier LC curves according to oligometastases from colorectal cancer and oligometastases from other cancers are shown in Fig. $2(p<0.001)$.

In the OS analyses, there were significant relationships of a poor survival rate with local failed cohort (ref. local controlled cohort; HR, 2.390; 95\% CI, 1.839-3.106; $p<$ 0.001 ), PS of 1 (ref. PS of 0; HR, 1.316; 95\% CI, 1.059$1.635 ; p=0.013$ ), PS of $2-3$ (ref. PS 0; HR, 2.008 ; $95 \%$ CI, 1.405-2.869; $\mathrm{p}<0.001$ ), oligometastases from the oesophagus (ref. colorectum; HR, 1.650; 95\% CI, 1.027$2.650 ; p=0.038$ ), squamous cell carcinoma pathology of the primary lesion (ref. adenocarcinoma; HR, 1.525; 95\% CI, 1.122-2.072; $p=0.006)$ and maximum oligometastatic tumour diameter (per $1-\mathrm{cm}$ increase; HR, 1.266;
95\% CI, 1.131-1.417; $\mathrm{p}<0.001$; Table 2). On the other hand, sync-oligometastases showed marginal significance (ref. oligo-recurrence, HR, 1.391; 95\% CI, 0.988-1.960; $p=0.058)$. In the landmark analyses, the LC status of the SBRT sites showed significant differences between the local controlled group and the local failed group at all landmark time points ( $p \leq 0.001$ at each point). The locally controlled group showed consistently longer survival than the locally failed group (Fig. 3).

\section{Discussion}

This study revealed the independent significance of the OS benefit in a locally controlled cohort compared to that in a locally failed cohort by using SBRT for 


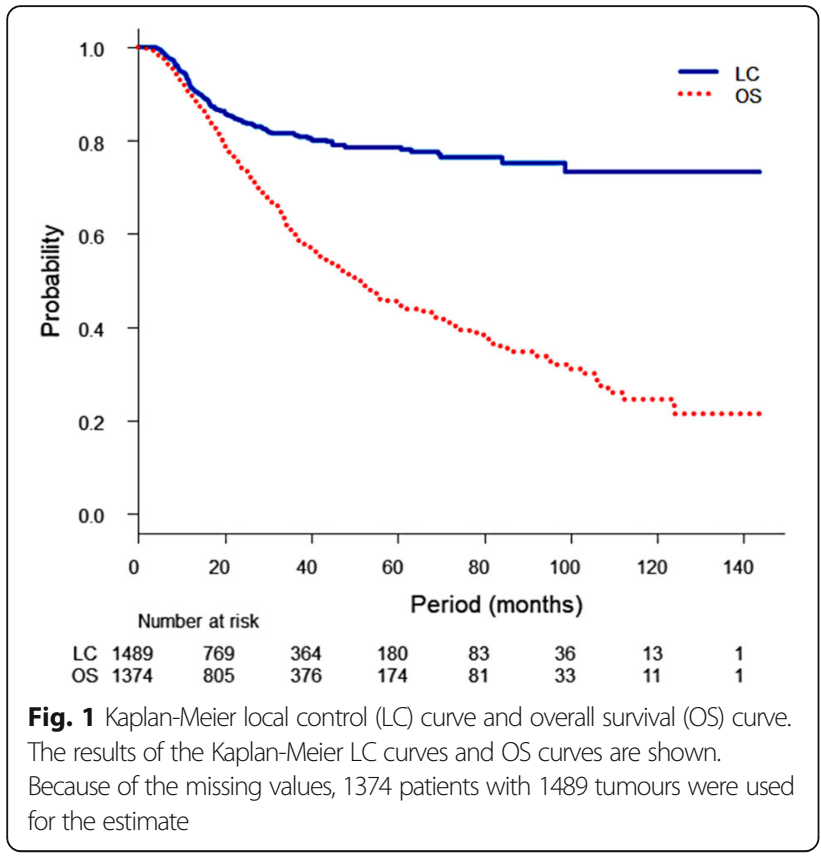

pulmonary oligometastases. In colorectal cancer, local failure of irradiated metastases has been reported to have a correlation with worse OS [17]. Analyses of the large survey data in this study expanded the evidence to oligometastases from various primary cancer types. It is certain that there is a situation in which metastasis-directed therapy works well and contributes to longer survival; therefore, $\mathrm{LC}$ of metastatic lesions is important in an oligometastatic situation. The LC rate for patients who received SBRT for pulmonary metastases has been shown to be relatively high in prospective trials, but similar results have not always been obtained in a real-world setting [18-20]. The LC analyses performed in this study provide several key factors for successful LC by SBRT.

It needs to be emphasized that SBRT should be given to appropriate patients. In the present study, among the inclusion criteria was that the primary lesion and extrathoracic lesions needed to be controlled before SBRT and all pulmonary oligometastases needed to be treated with local therapy. In a retrospective study in patients with synchronous oligometastatic (probably syncoligometastases) epidermal growth factor receptor (EGFR)-mutant non-small cell lung cancer who were treated with an EGFR-tyrosine kinase inhibitor, OS improved only in patients who received local ablative therapy for the primary lesion and for all oligometastatic lesions [21]. Thus, the number of metastases and the treatability of all lesions by local therapy are important. In metastatic prostate cancer, a survival benefit from definitive radiotherapy for the primary lesion was observed only among those with a low metastatic burden, and additional radiotherapy for all oligometastases showed

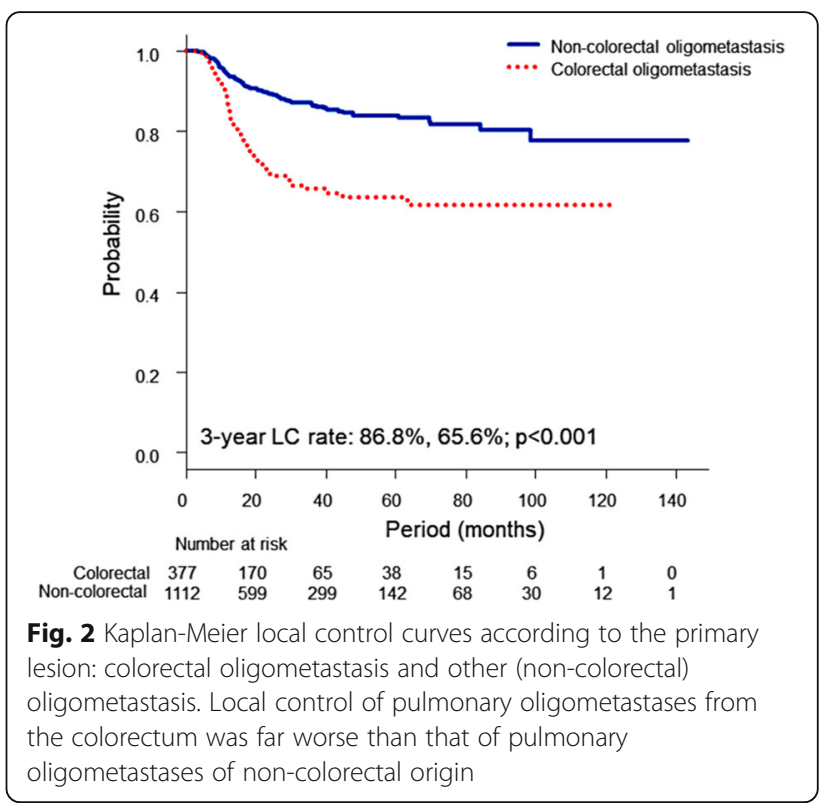

retrospectively better castration-resistant prostate cancer-free survival than radiotherapy for only the primary lesion [7, 22]. A recent consensus report proposed a maximum of five metastases and three organs as synchronous oligometastatic non-small cell lung cancer (probably sync-oligometastases) [23]. To provide metastasis-directed therapy well, recent phase 2 trials required thoughtful eligibility criteria, treating the primary lesion and all known oligometastases with local therapy [8-10, 24]. Appropriate selection of patients is important to obtain benefit from SBRT.

The collaborative and detailed analyses of this study have also revealed some factors that affect LC. The MVA for LC showed that the primary site, maximum tumour diameter treated by SBRT and dose calculation algorithm were significant factors affecting LC, and these factors confirmed previous findings [25-27]. Poor LC of metastatic lung tumours from the colorectum has been discussed because there are some reports of extremely low LC rates of colorectal metastases as well as reports of low LC rates of liver or bone metastases from the colorectum [27-32]. Interestingly, a German group reported that there was no significant difference in LC rates for colorectal metastases and non-colorectal metastases in the lung, but there was a significant difference in $\mathrm{LC}$ rates for those in the liver [20,33]. In this study, a large crude difference of approximately $20 \%$ was found between the LC rates for colorectal oligometastases and non-colorectal oligometastases (Fig. 2). Analysis of SBRT for pulmonary oligometastases from colorectal cancer showed that dose escalation improved LC [34]. Consideration should be given to possible ways to improve LC of colorectal oligometastases. 
The OTT of SBRT also showed a significant relationship with LC. The OTT of SBRT probably reflected both intervals of each treatment session of SBRT and the number of SBRT fractions. Considering that the number of fractions was not a significant factor in UVA, the significance of a longer OTT is mainly due to the intervals between each treatment session. A better effectiveness of longer intervals between each treatment session would be reasonable because it might reflect the effect of reoxygenation, which has an influence on tumour radiosensitivity $[35,36]$. SBRT sessions are often performed on consecutive days in Japan. However, the Radiation Therapy Oncology Group (RTOG) trial and another study required longer intervals in SBRT [23, 37]. Unfortunately, whether SBRT was performed on consecutive days or non-consecutive days was not investigated in this study, but appropriate intervals between sessions, such as $40 \mathrm{~h}$, might contribute to higher LC rates.
There are several limitations of this study. The retrospective nature of this study made all of the analyses subject to selection bias and confounding by indication. There was a considerable amount of missing data, the SBRT methods varied from centre to centre, the followup examinations and the evaluation of local failure were inconsistent, and there were unmeasured or uncontrolled factors. We could not investigate unlisted survey items, such as a central lung tumour or not, or the details of the history of extrathoracic lesions, such as the number of involved organs, patient comorbidities and dose-volume histogram analyses of the lung.

\section{Conclusions}

In conclusion, to achieve higher LC of pulmonary oligometastases by SBRT, the use of a type A algorithm should be avoided and a longer OTT of SBRT contributes to a higher $\mathrm{LC}$ rate. Tumour characteristics such as

Table 2 Multivariate Cox regression analysis of local control and overall survival

\begin{tabular}{|c|c|c|c|c|c|}
\hline \multirow[t]{2}{*}{ Factors } & \multirow[t]{2}{*}{ Covariate } & \multicolumn{2}{|l|}{ Local control } & \multicolumn{2}{|l|}{ Overall survival } \\
\hline & & $\mathrm{HR}(95 \% \mathrm{Cl})$ & $P$ value & $\mathrm{HR}(95 \% \mathrm{Cl})$ & $P$ value \\
\hline \multirow[t]{2}{*}{ Local status } & Controlled & - & - & reference & \\
\hline & Failed & - & - & $2.390(1.839-3.106)$ & $<0.001$ \\
\hline \multirow[t]{3}{*}{ ECOG PS } & 0 & - & - & reference & \\
\hline & 1 & - & - & $1.316(1.059-1.635)$ & 0.013 \\
\hline & $2-3$ & - & - & $2.008(1.405-2.869)$ & $<0.001$ \\
\hline \multirow[t]{5}{*}{ Primary lesion sites } & Colorectum & reference & & reference & \\
\hline & Lung & $0.413(0.274-0.622)$ & $<0.001$ & $0.936(0.685-1.280)$ & 0.681 \\
\hline & $H \& N$ & $0.194(0.077-0.489)$ & $<0.001$ & $0.905(0.556-1.474)$ & 0.690 \\
\hline & Oesophagus & $0.618(0.306-1.248)$ & 0.179 & $1.650(1.027-2.650)$ & 0.038 \\
\hline & Others & $0.337(0.208-0.546)$ & $<0.001$ & $1.208(0.863-1.691)$ & 0.270 \\
\hline \multirow[t]{3}{*}{ Pathology of primary lesion } & Adenoca. & - & - & reference & \\
\hline & SqCC & - & - & $1.525(1.122-2.072)$ & 0.006 \\
\hline & Others & - & - & $1.291(0.916-1.818)$ & 0.143 \\
\hline \multirow[t]{3}{*}{ Oligometastatic state } & Oligo-rec & - & - & reference & \\
\hline & Sync-oligo & - & - & $1.391(0.988-1.960)$ & 0.058 \\
\hline & Unclassified & - & - & $1.246(0.905-1.714)$ & 0.177 \\
\hline \multirow[t]{2}{*}{ Chemotherapy concurrent with SBRT } & Yes & $1.969(0.859-4.513)$ & 0.109 & - & - \\
\hline & No & reference & & - & - \\
\hline Maximum tumour diameter & Per $1 \mathrm{~cm}$ & $1.297(1.059-1.588)$ & 0.011 & $1.266(1.131-1.417)$ & $<0.001$ \\
\hline \multirow[t]{3}{*}{ Dose calculation algorithm } & Type A & reference & & - & - \\
\hline & Type B & $0.592(0.410-0.856)$ & 0.005 & - & - \\
\hline & Type C & $0.732(0.371-1.445)$ & 0.368 & - & - \\
\hline $\mathrm{BED}_{10}$ at isocenter & Per 10 Gy & $0.912(0.828-1.006)$ & 0.065 & - & - \\
\hline OTT of SBRT & Per 10 days & $0.610(0.385-0.966)$ & 0.035 & - & - \\
\hline
\end{tabular}

Abbreviations: HR Hazard ratio, Cl Confidence interval, ECOG Eastern Cooperative Oncology Group, PS Performance status, H\&N Head and neck, Adenoca. Adenocarcinoma, SqCC Squamous cell carcinoma, Oligo-rec. Oligo-recurrences, Sync-oligo Sync-oligometastases, SBRT Stereotactic body radiotherapy, BED Biological effective dose, OTT Overall treatment time 


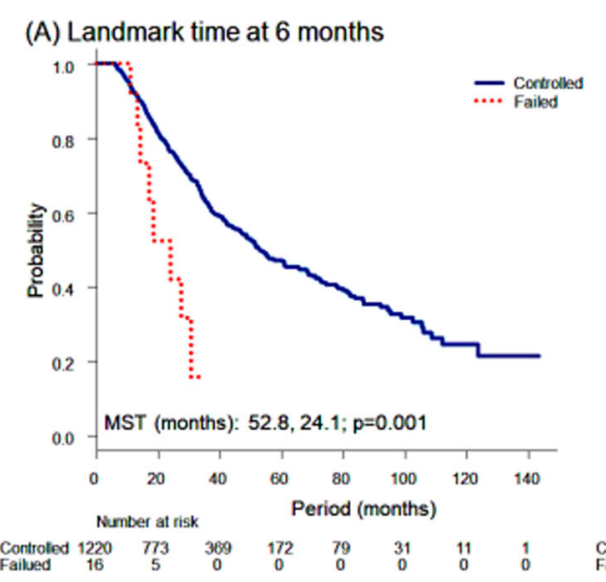

\section{(B) Landmark time at 1 year}

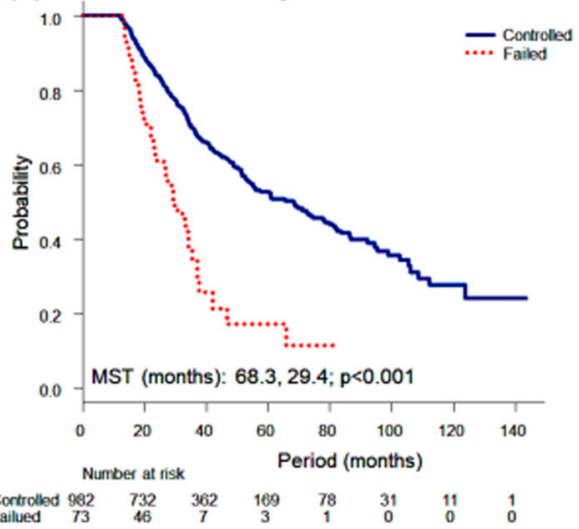

(C) Landmark time at 2 years

(D) Landmark time at 3 years
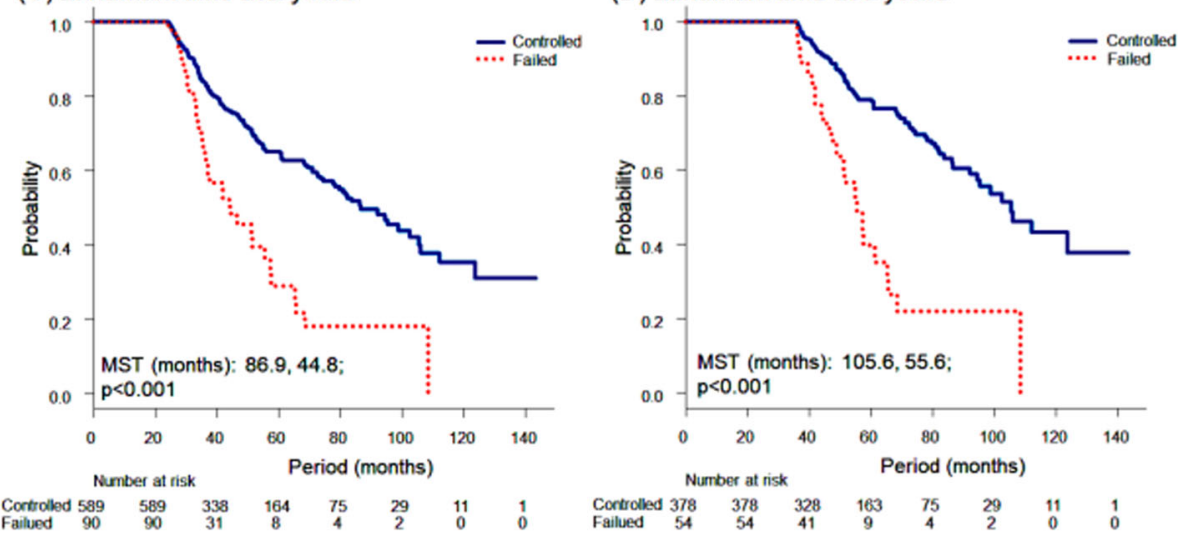

Fig. 3 Landmark analyses for OS to compare between a locally controlled cohort and a locally failed cohort. All the local failures after the landmark time and all the deaths before that time were ignored. The locally controlled group showed a consistent significantly longer survival than the locally failed group at each landmark time

small-size oligometastases and non-colorectal oligometastases also showed a higher $\mathrm{LC}$ rate. $\mathrm{LC}$ of pulmonary oligometastases by SBRT with a controlled primary lesion before SBRT had a survival benefit compared to the locally uncontrolled group, and LC status showed the highest HR in multivariate analysis for OS.

\section{Supplementary information}

Supplementary information accompanies this paper at https://doi.org/10. 1186/s12885-020-07514-9.

\section{Additional file 1.}

\section{Abbreviations}

LC: Local control; SBRT: Stereotactic body radiotherapy; BED: Biological effective dose; RECIST: Response Evaluation Criteria in Solid Tumors; FDGPET: ${ }^{18}$ F-Fluorodeoxyglucose Positron Emission Tomography; OS: Overall survival; Cl: Confidence interval; UVA: Univariate analysis; MVA: Multivariate analysis; AIC: Akaike information criterion; AE: Adverse event; PS: Performance status; OTT: Overall treatment time; IQR: Interquartile range; HR: Hazard ratio; EGFR: Epidermal growth factor receptor; RTOG: Radiation Therapy Oncology Group

\section{Acknowledgements}

We acknowledge the collaboration of many radiation oncologists in Japan. We thank Drs. Akira Anbai, Gencho Kuga, Hajime Ikeda, Hideya Yamazaki, Hidekazu Tanaka, Hisashi Kaizu, Hiroki Kobayashi, Hisao Kakuhara, Ichiro Ogino, Imi Takanashi, Junichi Yokouchi, Kana Kobayashi, Katsuyuki Shirai, Keisuke Fujimoto, Kenji Nagata, Kentaro Yamamoto, Koda Ryuichi, Kosuke Amano, Koutaro Terashima, Masaaki Yamashina, Masayoshi Yamada, Michiko Imai, Miyako Myojin, Nanae Yamaguchi, Nobuhiko Yoshikawa, Nobuhisa Mabuchi, Osamu Suzuki, Saeko Hirota, Satoshi Itasaka, Seiji Kubota, Shigetoshi Shimamoto, Shinichi Ogawa, Shinya Takemoto, Shizuko Ohashi, Syuji Otsu, Takanori Fukuda, Takashi Sakamoto, Takashi Kawanaka, Takuya Yamazaki, Tetsuo Nonaka, Tetsuo Saito, Tetsuya Inoue, Toshiki Kawamura, Toshinori Soejima, Tomoyasu Kumano, Toru Sakayauchi, Tsunehiko Kan, Yasuhiro Dekura, Yasuo Matsumoto, Yoshiaki Okamoto, Yoshisuke Matsuoka, Yo Ushijima, Yuko Shirata, Yumi Sato, Yu Takada and Yutaka Naoi.

\section{Authors' contributions}

Conception and design: YN and TY. Provision of study patients: TY, YN, MA, TS, KY1, MK, HY, MO, YM, HO, KY2, AN, KK and RO. Data analysis and interpretation: TY and KJ. Manuscript draft: TY. Manuscript editing and revision NY, MA, TS, KY1, MK, HY, MO, YM, HO, KY2, AN, KK, RO, AT and KJ. Final approval of the manuscript: All authors.

\section{Funding}

This study was supported by a Grant-in-aid for research on radiation oncology of JASTRO 2015-2016 which was provided by public corporation "Koueki 
Shadan Hojin Nihon Houshasenn Shuyou Gakkai" in Japanese. This funding was used to collect to the data from each institutions.

\section{Availability of data and materials}

The dataset used this study are currently unavailable because it contains materials in unpublished manuscripts.

\section{Ethics approval and consent to participate}

This study was approved by the ethical committee of a senior facility (Ethics Committee of Toho University Omori Medical Center, reference number: 27148). The need for informed consent was waived due to the study design, but all participating institutions were guaranteed the chance to opt-out of participating in this study by spreading information about the study via the Internet or posters, and opt-out consent was obtained from all patients.

\section{Consent for publication}

Not applicable.

\section{Competing interests}

YN has received lecturer fees from Janssen Pharmaceutical K.K. TY, MA, TS, KY1, MK, HY, MO, YM, HO, KY2, AN, KK, RO, AT and KJ declare no conflict of interest.

\section{Author details}

${ }^{1}$ Department of Radiation Oncology, Tohoku University Graduate School of Medicine, 1-1 Seiryo-machi, Aoba-ku, Sendai 980-8574, Japan. ${ }^{2}$ Department of Radiology, Toho University Omori Medical Center, 6-11-1 Omorinishi, Ota-ku, Tokyo 143-8540, Japan. ${ }^{3}$ Department of Public Health, Kurume University School of Medicine, 67 Asahi-machi, Kurume 830-0011, Japan. ${ }^{4}$ Department of Radiation Oncology, Hirosaki University, 1 Bunkyo-cho, Hirosaki 036-8560, Japan. ${ }^{5}$ Department of Radiation Oncology and Image-Applied Therapy, Kyoto University Graduate School of Medicine, 54 Shogoinkawahara-cho, Sakyo-ku, Kyoto 606-8501, Japan. ${ }^{6}$ Department of Radiation Oncology, Seirei Mikatahara General Hospital, 3453 Mikatahara-cho, Kita-ku, Hamamatsu 433-8558, Japan. ${ }^{7}$ Department of Radiation Oncology, Fukuyama City Hospital, 5-23-1 Zao-cho, Fukuyama 721-8511, Japan. ${ }^{8}$ Department of Radiology, University of Tokyo, 7-3-1 Hongo, Bunkyo-ku, Tokyo 113-8655, Japan. ${ }^{9}$ Department of Radiation Oncology, Shizuoka City Shimizu Hospital, 1231 Miyakami, Shimizu-ku, Shizuoka 424-8636, Japan.

${ }^{10}$ Department of Radiology, Nagoya City University, 1 Kawasumi, Mizuho-cho, Mizuho-ku, Nagoya 467-8601, Japan. "'Department of Radiology, Yamanashi University, 1110 Shimokato, Chuo 409-3898, Japan. ${ }^{12}$ Department of Radiology, University of Occupational and Environmental Health, 1-1 Iseigaoka, Yahatanishi-ku, Kitakyushu 807-8555, Japan. ${ }^{13}$ Department of Radiation Oncology, Shikoku Cancer Center, 160 Minamiumemoto-machi, Matsuyama 791-0280, Japan. ${ }^{14}$ Department of Proton Beam Therapy, Okayama University, 2-5-1 Shikata-cho, Kitaku, Okayama 700-8558, Japan. ${ }^{15}$ Department of Radiology, Miyakojima IGRT Clinic, 1-16-22 Miyakojima-hondori, Miyakojima-ku, Osaka 534-0021, Japan.

Received: 14 June 2020 Accepted: 8 October 2020

Published online: 14 October 2020

\section{References}

1. Flanigan RC, Salmon SE, Blumenstein BA, Bearman SI, Roy V, McGrath PC, Caton JR Jr, Munshi N, Crawford ED. Nephrectomy followed by interferon alfa- $2 \mathrm{~b}$ compared with interferon alfa-2b alone for metastatic renal-cell cancer. N Engl J Med. 2001:345:1655-9.

2. Le Scodan R, Stevens D, Brain E, Floiras JL, Cohen-Solal C, De La Lande B, Tubiana-Hulin M, Yacoub S, Gutierrez M, Ali D, Gardner M, Moisson P, et al. Breast cancer with synchronous metastases: survival impact of exclusive locoregional radiotherapy. J Clin Oncol. 2009;27:1375-81.

3. Xu H, Xia Z, Jia X, Chen K, Li D, Dai Y, Tao M, Mao Y. Primary tumor resection is associated with improved survival in stage IV colorectal Cancer: an instrumental variable analysis. Sci Rep. 2015;5:16516.

4. Rusthoven CG, Jones BL, Flaig TW, Crawford ED, Koshy M, Sher DJ, Mahmood U, Chen RC, Chapin BF, Kavanagh BD, et al. Improved survival with prostate radiation in addition to androgen deprivation therapy for men with newly diagnosed metastatic prostate Cancer. J Clin Oncol. 2016; 34:2835-42.
5. Tao L, Yuan C, Ma Z, Jiang B, Xiu D. Surgical resection of a primary tumor improves survival of metastatic pancreatic cancer: a population-based study. Cancer Manag Res. 2017;9:471-9.

6. Hellman S, Weichselbaum RR. Oligometastases. J Clin Oncol. 1995;13:8-10.

7. Parker CC, James ND, Brawley CD, Clarke NW, Hoyle AP, Ali A, Ritchie AWS, Attard G, Chowdhury S, Cross W, et al. Radiotherapy to the primary tumour for newly diagnosed, metastatic prostate cancer (STAMPEDE): a randomised controlled phase 3 trial. Lancet. 2018;392:2353-66.

8. Ost P, Reynders D, Decaestecker K, Fonteyne V, Lumen N, De Bruycker A, Lambert B, Delrue L, Bultijnck R, Claeys T, et al. Surveillance or metastasisdirected therapy for Oligometastatic prostate Cancer recurrence: a prospective, randomized, multicenter phase II trial. J Clin Oncol. 2018;36: $446-53$.

9. Gomez DR, Blumenschein GR Jr, Lee JJ, Hernandez M, Ye R, Camidge DR, Doebele RC, Skoulidis F, Gaspar LE, Gibbons DL, et al. Local consolidative therapy versus maintenance therapy or observation for patients with oligometastatic non-small-cell lung cancer without progression after firstline systemic therapy: a multicentre, randomised, controlled, phase 2 study. Lancet Oncol. 2016;17:1672-82

10. Iyengar P, Wardak Z, Gerber DE, Tumati V, Ahn C, Hughes RS, Dowell JE, Cheedella N, Nedzi L, Westover KD, et al. Consolidative radiotherapy for limited metastatic non-small-cell lung Cancer: a phase 2 randomized clinical trial. JAMA Oncol. 2018;4:e173501.

11. Niibe Y, Hayakawa K. Oligometastases and oligo-recurrence: the new era of cancer therapy. Jpn J Clin Oncol. 2010;40:107-11.

12. Niibe Y, Chang JY. Novel insights of oligometastases and oligo-recurrence and review of the literature. Pulm Med. 2012;2012:261096.

13. Niibe $Y$, Yamamoto T, Onishi H, Yamashita H, Katsui K, Matsumoto Y, Oh RJ, Aoki M, Shintani T, Yamada K, et al. Pulmonary Oligometastases treated by stereotactic body radiation therapy: a Nationwide survey of 1,378 patients. Anticancer Res. 2020;40:393-9.

14. Kanda Y. Investigation of the freely available easy-to-use software 'EZR' for medical statistics. Bone Marrow Transplant. 2013;48:452-8.

15. Anderson JR, Cain KC, Gelber RD. Analysis of survival by tumor response. J Clin Oncol. 1983;1:710-9.

16. Dafni U. Landmark analysis at the 25-year landmark point. Circ Cardiovasc Qual Outcomes. 2011;4:363-71.

17. Franzese C, Comito T, Toska E, Tozzi A, Clerici E, De Rose F, Franceschini D, Navarria P, Reggiori G, Tomatis $\mathrm{S}$, et al. Predictive factors for survival of oligometastatic colorectal cancer treated with stereotactic body radiation therapy. Radiother Oncol. 2019;133:220-6.

18. Rusthoven KE, Kavanagh BD, Burri SH, Chen C, Cardenes H, Chidel MA, Pugh TJ, Kane M, Gaspar LE, Schefter TE. Multi-institutional phase I/II trial of stereotactic body radiation therapy for lung metastases. J Clin Oncol. 2009; 27:1579-84.

19. Nuyttens JJ, van der Voort van Zyp NC, Verhoef C, Maat A, van Klaveren RJ, van der Holt B, Aerts J, Hoogeman M. Stereotactic body radiation therapy for oligometastases to the lung: a phase 2 study. Int J Radiat Oncol Biol Phys. 2015;91:337-43.

20. Rieber J, Streblow J, Uhlmann L, Flentje M, Duma M, Ernst I, Blanck O, Wittig A, Boda-Heggemann J, Krempien R, et al. Stereotactic body radiotherapy (SBRT) for medically inoperable lung metastases-a pooled analysis of the German working group "stereotactic radiotherapy". Lung Cancer. 2016;97: $51-8$.

21. Xu Q, Zhou F, Liu H, Jiang T, Li X, Xu Y, Zhou C. Consolidative local ablative therapy improves the survival of patients with synchronous Oligometastatic NSCLC harboring EGFR activating mutation treated with first-line EGFR-TKIs. J Thorac Oncol. 2018;13:1383-92.

22. Tsumura H, Ishiyama H, Tabata KI, Sekiguchi A, Kawakami S, Satoh T, Kitano M, Iwamura M. Long-term outcomes of combining prostate brachytherapy and metastasis-directed radiotherapy in newly diagnosed oligometastatic prostate cancer: a retrospective cohort study. Prostate. 2019;79:506-14.

23. Dingemans AC, Hendriks LEL, Berghmans T, Levy A, Hasan B, Faivre-Finn C, Giaj-Levra M, Giaj-Levra N, Girard N, Greillier L, et al. Definition of synchronous Oligometastatic non-small cell lung Cancer-a consensus report. J Thorac Oncol. 2019;14:2109-19.

24. Palma DA, Olson R, Harrow S, Gaede S, Louie AV, Haasbeek C, Mulroy L, Lock M, Rodrigues GB, Yaremko BP, et al. Stereotactic ablative radiotherapy versus standard of care palliative treatment in patients with oligometastatic cancers (SABR-COMET): a randomised, phase 2, open-label trial. Lancet. 2019;393:2051-8. 
25. Takeda A, Kunieda E, Ohashi T, Aoki Y, Koike N, Takeda T. Stereotactic body radiotherapy (SBRT) for oligometastatic lung tumors from colorectal cancer and other primary cancers in comparison with primary lung cancer. Radiother Oncol. 2011;101:255-9.

26. Helou J, Thibault I, Poon I, et al. Stereotactic ablative radiation therapy for pulmonary metastases: histology, dose, and indication matter. Int J Radiat Oncol Biol Phys. 2017;98:419-27 PubMed PMID: 28463162.

27. Helou J, Thibault I, Poon I, Chiang A, Jain S, Soliman H, Erler D, Yeung L, Cheung P. Influence of institutional experience and technological advances on outcome of stereotactic body radiation therapy for Oligometastatic lung disease. Int J Radiat Oncol Biol Phys. 2016;98:511-20.

28. Takeda A, Sanuki N, Tsurugai Y, Oku Y, Aoki Y. Stereotactic body radiotherapy for patients with oligometastases from colorectal cancer: riskadapted dose prescription with a maximum dose of 83-100 Gy in five fractions. J Radiat Res. 2016:57:400-5.

29. Jingu K, Matsushita H, Yamamoto T, Umezawa R, Ishikawa Y, Takahashi N, Katagiri Y, Takeda K, Kadoya N. Stereotactic radiotherapy for pulmonary Oligometastases from colorectal Cancer: a systematic review and metaanalysis. Technol Cancer Res Treat. 2018;17:1533033818794936.

30. Ahmed KA, Caudell JJ, El-Haddad G, Berglund AE, Welsh EA, Yue B, Hoffe SE, Naghavi AO, Abuodeh YA, Frakes JM. Radiosensitivity differences between liver metastases based on primary histology suggest implications for clinical outcomes after stereotactic body radiation therapy. Int J Radiat Oncol Biol Phys. 2016;95:1399-404.

31. Ito K, Ogawa H, Shimizuguchi T, Nihei K, Furuya T, Tanaka H, Karasawa K. Stereotactic body radiotherapy for spinal metastases: clinical experience in 134 cases from a single Japanese institution. Technol Cancer Res Treat. 2018;17:1533033818806472.

32. Hong JC, Ayala-Peacock DN, Lee J, Blackstock AW, Okunieff P, Sung MW, Weichselbaum RR, Kao J, Urbanic JJ, Milano MT, et al. Classification for longterm survival in oligometastatic patients treated with ablative radiotherapy: a multi-institutional pooled analysis. PLoS One. 2018;13:e0195149.

33. Andratschke $\mathrm{N}$, Alheid $\mathrm{H}$, Allgäuer $\mathrm{M}$, Becker $\mathrm{G}$, Blanck $\mathrm{O}$, Boda-Heggemann J, Brunner T, Duma M, Gerum S, Guckenberger M, et al. The SBRT database initiative of the German Society for Radiation Oncology (DEGRO): patterns of care and outcome analysis of stereotactic body radiotherapy (SBRT) for liver oligometastases in 474 patients with 623 metastases. BMC Cancer. 2018;18:283.

34. Jingu K, Matsuo Y, Onishi H, Yamamoto T, Aoki M, Murakami Y, Yamashita H, Kakuhara H, Nemoto K, Sakayauchi T, et al. Dose escalation improves outcome in stereotactic body radiotherapy for pulmonary Oligometastases from colorectal Cancer. Anticancer Res. 2017;37:2709-13.

35. Brown JM, Wilson WR. Exploiting tumour hypoxia in cancer treatment. Nat Rev Cancer. 2004;4:437-47.

36. Kallman RF. The phenomenon of reoxygenation and its implications for fractionated radiotherapy. Radiology. 1972;105:135-42.

37. Timmerman R, Paulus R, Galvin J, Michalski J, Straube W, Bradley J, Fakiris A, Bezjak A, Videtic $G$, Johnstone $D$, et al. Stereotactic body radiation therapy for inoperable early stage lung cancer. JAMA. 2010;303:1070-6.

\section{Publisher's Note}

Springer Nature remains neutral with regard to jurisdictional claims in published maps and institutional affiliations.

\section{Ready to submit your research? Choose BMC and benefit from}

- fast, convenient online submission

- thorough peer review by experienced researchers in your field

- rapid publication on acceptance

- support for research data, including large and complex data types

- gold Open Access which fosters wider collaboration and increased citations

- maximum visibility for your research: over $100 \mathrm{M}$ website views per year

At $\mathrm{BMC}$, research is always in progress.

Learn more biomedcentral.com/submissions 